\title{
Bilateral Anterior Shoulder Dislocation
}

\author{
Yuk Chuen Siu ${ }^{1}$; Tun Hing Lui ${ }^{1,}$ \\ ${ }^{1}$ Department of Orthopaedics and Traumatology, North District Hospital, Sheung Shui, China \\ ${ }^{*}$ Corresponding author: Tun Hing Lui, Department of Orthopaedics and Traumatology, North District Hospital, Sheung Shui, China. Tel: +86-85226837588, Fax: +86-85226837588, \\ E-mail: luithderek@yahoo.co.uk
}

Received: February 11, 2014; Revised: May 26, 2014; Accepted: August 9, 2014

\begin{abstract}
Introduction: Unilateral anterior shoulder dislocation is one of the most common problems encountered in orthopedic practice. However, simultaneous bilateral anterior dislocation of the shoulders is quite rare.

Case Presentation: We report a case of a 75-year-old woman presented with simultaneous bilateral anterior shoulder dislocation following a trauma, complicated with a traction injury to the posterior cord of the brachial plexus.

Conclusions: Bilateral anterior shoulder dislocation is very rare. The excessive traction force during closed reduction may lead to nerve palsy. Clear documentation of neurovascular status and adequate imaging before and after a reduction should be performed.
\end{abstract}

Keywords:Shoulder; Dislocation; Brachial Plexus

\section{Introduction}

Anterior shoulder dislocation is one of the most common problems encountered in daily orthopedic practice and needed to be treated promptly. Bilateral anterior shoulder dislocation is a very rare occurrence and can be easily missed if the patients are not carefully examined. The adequate imaging and detailed examination of the neurovascular system are also required to rule out any fracture and neurovascular injury. The following case report described a case of simultaneous bilateral anterior shoulder dislocation after injury, complicated with traction injury to the posterior cord of brachial plexus.

\section{Case Presentation}

A 75-year-old woman with a history of good past health presented to the emergency department complaining of pain in both shoulders. She lost her balance and fell forward while she was doing the bench push-up at the park. She hit on bench with both shoulders in extension, abduction and external rotation position. She noted severe bilateral shoulder pain afterward. Physical examination revealed forehead hematoma and the squaring of bilateral shoulders was also noted. Both shoulders were irritable with a restricted range of movement in all aspects. Diagnosis of bilateral anterior shoulder dislocation without associated fracture was confirmed by imaging (Figure 1). Closed reduction was performed in the emergency department under sedation, successful reduction of both shoulders was also confirmed with imaging (Figure 2) and then the patient was admitted to our department. The patient complained of the recurrent right shoulder pain after admission. On examination, the recurrent right shoulder anterior dislocation was suspected and confirmed with imaging. Closed reduction was performed using the Kocher's technique under fluoroscopy. Left wrist drop was also noticed (Figure 3). On detailed examination, numbness along the posterior aspect of forearm, weak triceps action and complete loss of left wrist finger extension were noted. A traction injury to the posterior cord was suspected. The nerve conduction test (NCT) and magnetic resonance imaging (MRI) showed the left brachial plexus injury together with bilateral shoulder dislocation. Both shoulders were immobilized with a shoulder immobilizer and a dynamic wrist splint was applied to the deformed wrist joint. The NCT was performed four months post-injury and the mild motor abnormality of left radial nerve was noted. MRI scans of bilateral shoulders and bilateral brachial plexus were performed six months post-injury. It showed Hill Sachs defect of the right humeral head and focal full thickness tear of the right supraspinatus tendon (Figure 4). There was also a complete rupture of the left supraspinatus tendon with proximal retraction of $3.5 \mathrm{~cm}$ (Figure 5). No significant finding was noted in the brachial plexus except perineural cysts over $\mathrm{C} 8$ and $\mathrm{T} 1$ nerve root. The patient was referred to physiotherapy and occupational therapy for rehabilitation. The shoulder immobilizers were kept for six weeks and the active-assisted mobilization was then started. Electrical stimulation of the affected muscle was performed to prevent muscle atrophy. At follow-up, 6 weeks post-injury, the patient reported an improvement in bilateral shoulder pain and no recurrent shoulder

Copyright (C) 2014, Kashan University of Medical Sciences. This is an open-access article distributed under the terms of the Creative Commons Attribution-NonCommercial 4.0 International License (http://creativecommons.org/licenses/by-nc/4.0/) which permits copy and redistribute the material just in noncommercial usages, provided the original work is properly cited. 


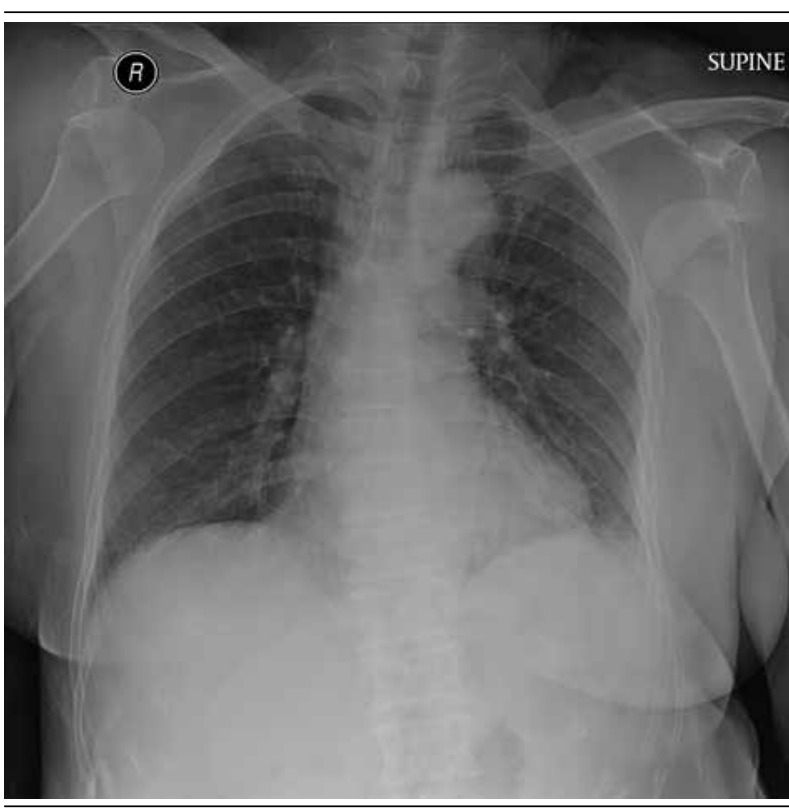

Figure 1. Injury Film Showed Bilateral Shoulder Dislocation

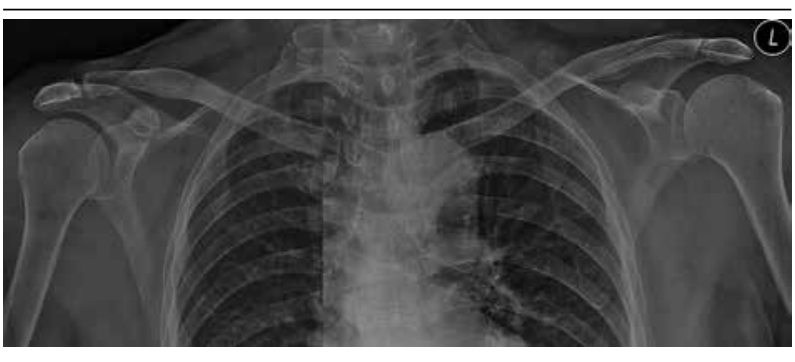

Figure 2. Post Closed Reduction Radiographs of Both Shoulders

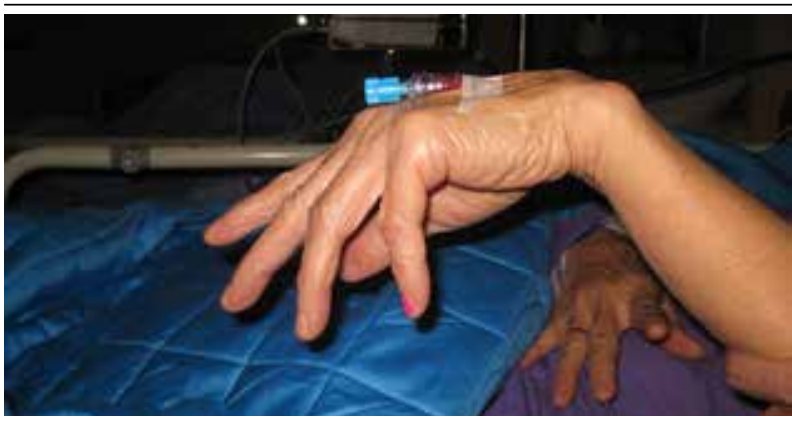

Figure 3. Left Wrist Drop

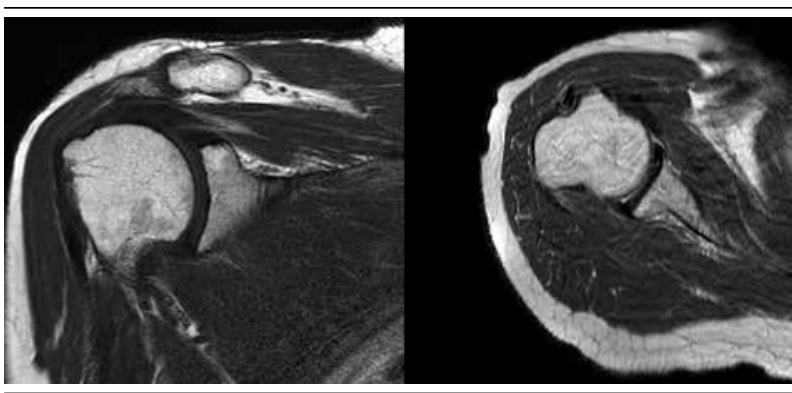

Figure 4. MRI Right Shoulder Showed Hill-Sachs Defect of the Humeral Head and Focal Full Thickness Tear of the Supraspinatus Tendon

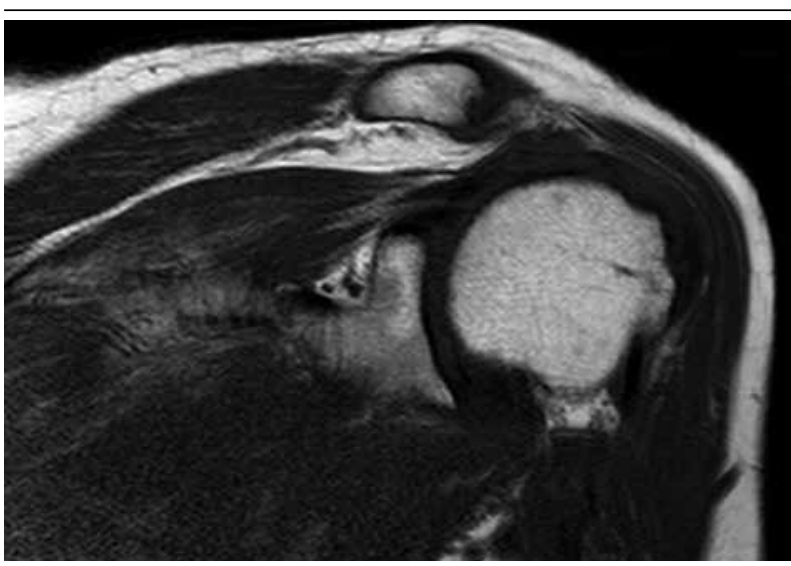

Figure 5. MRI Left Shoulder Showed a Complete Rupture of the Supraspinatus Tendon With Proximal Tendinous Retraction

dislocation. There was also an improvement in the numbness of the left upper limb and the power of left wrist and finger extension (both reached grade $4 / 5$ ). At follow- up, 4 months post-injury, the patient was able to flex both shoulders to 145 degrees and abduct them to 160 degrees.

\section{Discussion}

Simultaneous bilateral anterior shoulder dislocation is a rare condition. Bilateral shoulder dislocation was first described in 1902 in patient with the excessive muscular contractions due to Camphor overdose (1). Most of them are case report or small series in the literature (2-28) (Table 1). In contrast, bilateral posterior shoulder dislocation occurs more frequently, and is usually due to electrical shock, seizures or other reasons, which lead to vigorous involuntary muscle contraction (3). Bilateral anterior shoulder dislocation occurs mainly due to trauma to the shoulders in the extension, abduction and external rotation positions $(2,20,25)$, which is exactly the same injury mechanism as our reported case. Other mechanism of injury is the traction in forward flexion of the shoulder $(2,24,25,28)$. Many of the reported cases are sport-related injuries including weight-lifting training $(4,6,20)$, backstroke swimming (8), chin-up exercise (24) and horse riding (2). The injury can be trivial, especially in elderly as in this case (9). Besides traumatic causes, bilateral anterior shoulder dislocation can follow hypoglycemic convulsion (11) or epileptic seizure $(14,17,21)$. The posterior dislocations are more common after seizure since the contraction of the relatively weak external rotators and the posterior fibers of the deltoid are overcome by the more powerful internal rotator. The succeeding adduction and internal rotation usually causes the humeral head to dislocate posteriorly (21). Bilateral anterior dislocation following a seizure may be from the trauma of the shoulders striking the floor after the collapse rather than due to the muscle contractions (21). Loss of consciousness after the seizure will not allow the patient to react and reflexly protect one of his arms by exposing the other (21). Clinical findings of an anterior dislocation shoulder in- 
clude squaring of the shoulder and a positive Dugas test (the hand of the affected shoulder cannot reach the contralateral shoulder)(18). Asymmetry of the joint typically heralds a dislocation. When bilateral dislocation occurs, this clinical asymmetry is absent and leading to missing diagnosis (27). The bilateral anterior shoulder dislocation can be associated with fracture of the coracoid process or greater tuberosity $(13,19,21,26,28)$. MRI in the acute phase plays a key role in the diagnosis of non-displaced fractures, as well as labral tears and Hill-Sachs lesions. Awareness of the associated injury is important in order to better approach treatment options, avoiding coracoid nonunion and chronic glenohumeral instability (19).

Most of the injuries have been treated by closed reduction and various period of immobilization with good clinical outcomes. The Spaso technique has been recommended $(18,23)$. The dislocated arm is grasped around the wrist and while maintaining vertical traction, the shoulder is slightly rotated externally $(18,23)$. It facilitated reduction as the amount of force used in this method is less compared with the Kochers method, the pain experienced by the patient is also less. The severe muscle spasm resulting from pain, which might prevent reduction by the Kochers method, can be avoided (18).

The brachial plexus injury after anterior shoulder dislocation is also a rare complication $(9,15)$. The mechanism of injury is mainly a traction injury to the brachial plexus (9). When the humeral head was dislocated, the nerves are stretched and are under great tension (29). In our case, the flexed position of the elbows with traction of the shoulder during the closed reduction caused a great tension over posterior cord resulting in a posterior cord traction injury and consequently the patient presented with forearm numbness and wrist drop. The MRI/NCT could be considered to confirm the diagnosis.

Patient suffered from this kind of brachial plexus palsy are initially treated conservatively. Regular interval examination to look for any clinical recovery is recommended. For those patients who do not show any sign of recovery at 3-6 months after the injury may need to consider for surgical exploration (30). Surgery is recommended to perform three weeks to six months after injury. Secondary suture or even nerve grafting may be needed, which depends on the length of the nerve gapping and surrounding soft tissue condition (31).

One special point for this case was that patient actually could not clearly remember when exactly the neurological symptoms appeared. And it was also not clearly documented about the neurological status in the case notes of the emergency department. Patient noted some left upper limb weakness and numbness initially after the injury and then suffered from the complete left wrist drop and finger drop after the second closed reduction of left shoulder using the Kocher's method. Therefore, the excessive force used in reduction may be one of the contributing factors for the injury of the posterior cord of the brachial plexus in this case. In Kocher's method, traction force was applied on the arm and it was abducted. Then the arm was externally rotated, adducted and then internally rotated. The excessive traction force, which was applied may lead to nerve palsy and even proximal humeral fracture (32). Therefore, clear documentation of neurovascular status and adequate imaging before and after a reduction should be performed.

\begin{tabular}{|c|c|c|c|c|c|}
\hline Case Report & Gender/Age, $y$ & Chronicity & Etiology & Associated Injury & Treatment \\
\hline Mehta and Kottamasu (14) & $\mathrm{M} / 53$ & acute & $\mathrm{T}$ & nil & CR, I, physio \\
\hline Maffulli and Mikhail (4) & $\mathrm{M} / 31$ & acute & $\mathrm{T}$ & nil & not available \\
\hline Marty et al. (13) & Not reported & acute & IMC & nil & ORIF \\
\hline Cresswell and Smith (19) & $\mathrm{M} / 31$ & acute & $\mathrm{T}$ & nil & CR, I x 6 weeks, physio \\
\hline Dinopoulos et al. (27) & $\mathrm{F} / 76$ & acute & $\mathrm{T}$ & 3 part fracture of right proximal humerus & $\begin{array}{c}\text { CR, I (left side x } 1 \text { week, right side } \\
\text { x } 3 \text { weeks), physio }\end{array}$ \\
\hline Cottias et al. (12) & $\mathrm{M} / 33$ & acute & IMC & $\begin{array}{l}\text { bilateral fractures of the greater tuberos- } \\
\text { ity and tip of the coracoid process }\end{array}$ & $\begin{array}{l}\text { CR left shoulder + ORIF right } \\
\text { shoulder }\end{array}$ \\
\hline Esenkaya et al. (6) & $\mathrm{M} / 22$ & acute & $\mathrm{T}$ & nil & Not available \\
\hline Yuen and Tung (22) & $\mathrm{M} / 41$ & acute & IMC & nil & CR \\
\hline Dunlop (3) & $\mathrm{F} / 91$ & acute & $\mathrm{T}$ & nil & CR, I x 1 week \\
\hline Singh and Kumar (17) & $\mathrm{M} / 21$ & acute & $\mathrm{T}$ & nil & $\mathrm{CR}, \mathrm{I}$ x 3 weeks \\
\hline Devalia and Peter (28) & $\mathrm{M} / 43$ & acute & $\mathrm{T}$ & right greater tuberosity fracture & CR, I x 4 weeks \\
\hline Ngim et al. (10) & $\mathrm{F} / 65$ & acute & $\mathrm{T}$ & nil & CR, I x 3 weeks \\
\hline Ozcelik et al. (11) & $\mathrm{M} / 20$ & acute & IMC & greater tuberosity fracture & CR, I x 6 weeks \\
\hline Bellazzini and Deming (21) & $\mathrm{M} / 32$ & acute & Non-T & nil & $\mathrm{CR}$ \\
\hline Turhan and Demirel (2) & $\mathrm{M} / 46$ & acute & $\mathrm{T}$ & nil & CR, I x 6 weeks, physio \\
\hline Lasanianos and Mouzopoulos (20) & $\mathrm{M} / 25$ & chronic & IMC & greater tuberosity fracture & $\begin{array}{l}\text { CR, IF of left greater tuberosity } \\
\text { fracture, I x } 2 \text { weeks, physio }\end{array}$ \\
\hline Felderman et al. (23) & $\mathrm{F} / 44$ & acute & $\mathrm{T}$ & nil & CR, I, physio \\
\hline Kalkan et al.(9) & $\mathrm{F} / 64$ & acute & $\mathrm{T}$ & left brachial plexus injury & CR, I x 3 weeks, physio \\
\hline Kalkan et al. (9) & $\mathrm{F} / 65$ & acute & $\mathrm{T}$ & nil & CR, I x 3 weeks, physio \\
\hline Abdulkadir et al. (8) & $\mathrm{M} / 35$ & chronic & IMC & bilateral brachial plexus injury & patient refused operation \\
\hline
\end{tabular}


Siu YC et al.

\begin{tabular}{|c|c|c|c|c|c|}
\hline Tripathy et al. (5) & not reported & acute & $\mathrm{T}$ & nil & $\mathrm{CR}, \mathrm{I}$ \\
\hline Tripathy et al. (5) & not reported & acute & IMC & nil & $\mathrm{CR}, \mathrm{I}$ \\
\hline Dlimi et al. (15) & $\mathrm{M} / 20$ & acute & $\mathrm{T}$ & nil & CR, I x 3 weeks, physio \\
\hline Mofidi et al. (16) & $\mathrm{M} / 30$ & acute & IMC & mandible fracture & $\mathrm{CR}$ \\
\hline Moughty and O'Connor (26) & $\mathrm{M} / 34$ & acute & $\mathrm{T}$ & nil & $\mathrm{CR}$ \\
\hline Nourredine et al. (7) & $\mathrm{M} / 70$ & acute & $\mathrm{T}$ & nil & CR, I x 4 weeks, physio \\
\hline Taneja et al. (18) & $\mathrm{M} / 37$ & acute & IMC & nil & CR, I x 2 weeks, physio \\
\hline Meena et al. (25) & $\mathrm{M} / 24$ & acute & $\mathrm{T}$ & left greater tuberosity fracture & $\begin{array}{l}\text { CR, I (right side x } 1 \text { week, left side } \\
\text { x } 6 \text { weeks) }\end{array}$ \\
\hline Ballesteros et al. (24) & $\mathrm{F} / 74$ & acute & $\mathrm{T}$ & nil & CR, I x 3 weeks, physio \\
\hline Ballesteros et al. (24) & $\mathrm{M} / 17$ & acute & $\mathrm{T}$ & nil & CR, I x 2 weeks, physio \\
\hline
\end{tabular}

${ }^{a}$ Abbreviations: T, traumatic; IMC, involuntary muscle contraction; CR, closed reduction; OR, open reduction; IF, internal fixation; I, immobilization.

\section{Authors' Contributions}

Dr Yuk Chuen Siu prepared the manuscript and performed the literature review; Dr Tun Hing Lui collected the clinical data and supervised the work of Dr Yuk Chuen Siu.

\section{References}

1. Mynter H. XIV. Subacromial Dislocation from Muscular Spasm. Ann Surg. 1902;36(1):117-9.

2. Turhan E, Demirel M. Bilateral anterior glenohumeral dislocation in a horse rider: a case report and a review of the literature. Arch Orthop Trauma Surg. 2008;128(1):79-82.

3. Dunlop CC. Bilateral anterior shoulder dislocation--a case report and review of the literature. Acta Orthop Belg. 2002;68(2):168-70.

4. Maffulli N, Mikhail HM. Bilateral anterior glenohumeral dislocation in a weight lifter. Injury.1990;21(4):254-6.

5. Tripathy SK, Sen RK, Aggarwal S, Dhatt SS, Tahasildar N. Simultaneous bilateral anterior shoulder dislocation: report of two cases and review of the literature. Chin J Traumatol. 2011;14(5):312-5.

6. Esenkaya I, Tuygun H, Turkmen IM. Bilateral anterior shoulder dislocation in a weight lifter. Phys Sportsmed. 2000;28(3):93-100.

7. Nourredine H, El Sayad M, Gull S, Davies AP. Bilateral anterio shoulder dislocation. BMJ Case Rep. 2013;2013.

8. Abdulkadir AY, Adesiyun OA, Jimoh OR, Amole AO. Chronic bilateral anterior shoulder dislocation. S Afr Med J. 2009;99(5):313.

9. Kalkan T, Demirkale I, Ocguder A, Unlu S, Bozkurt M. [Bilatera anterior shoulder dislocation in two cases due to housework accidents]. Acta Orthop Traumatol Turc. 2009;43(3):260-3.

10. Ngim NE, Udorroh EG, Udosen AM. Acute bilateral anterior shoulder dislocation following domestic assault-case report West Afr J Med 2006:25(3):256-7.

11. Ozcelik A, Dincer M, Cetinkanat H. Recurrent bilateral dislocation of the shoulders due to nocturnal hypoglycemia: a case report. Diabetes Res Clin Pract. 2006;71(3):353-5.

12. Cottias P, le Bellec Y, Jeanrot C, Imbert P, Huten D, Masmejean EH. Fractured coracoid with anterior shoulder dislocation and greater tuberosity fracture--report of a bilateral case. Acta Orthop Scand. 2000;71(1):95-7.

13. Marty B, Simmen HP, Kach K, Trentz O. [Bilateral anterior shoulder dislocation fracture after an epileptic seizure. A case report] Unfallchirurg. 1994;97(7):382-4.

14. Mehta MP, Kottamasu SR. Anterior dislocation of the shoulders with bilateral brachial plexus injury. Ann Emerg Med. 1989;18(5):589-91.

15. Dlimi F, Rhanim A, Lahlou A, Kharmaz M, Ouadghiri M, El Bardouni A, et al. Bilateral anterior dislocation of the shoulders at the start of a backstroke competition. J Orthop Traumatol. 2012;13(1):47-9.
16. Mofidi M, Kianmehr N, Farsi D, Yazdanpanah R, Majidinezhad S, Asadi P. An unusual case of bilateral anterior shoulder and mandible dislocations. Am JEmerg Med. 2010;28(6):745 e1-2.

17. Singh S, Kumar S. Bilateral anterior shoulder dislocation: a case report. EurJEmerg Med. 2005;12(1):33-5.

18. Taneja AK, Pecci Neto L, Skaf A. Bilateral anterior glenohumera dislocation and coracoid processes fracture after seizure: acute MRI findings of this rare association. Clin Imaging. 2013;37(6):1131

19. Cresswell TR, Smith RB. Bilateral anterior shoulder dislocation in bench pressing: an unusual cause. BrJ Sports Med.1998;32(1):71-

20. Lasanianos N, Mouzopoulos G. An undiagnosed bilateral anterior shoulder dislocation after a seizure: a case report. Cases J. 2008;1(1):342.

21. Bellazzini MA, Deming DA. Bilateral anterior shoulder dislocation in a young and healthy man without obvious cause. Am Emerg Med. 2007;25(6):734 e1-3.

22. Yuen MC, Tung WK. The use of the Spaso technique in a patient with bilateral dislocations of shoulder. Am J Emerg Med 2001;19(1):64-6.

23. Felderman $\mathrm{H}$, Shih R, Maroun V. Chin-up-induced bilatera anterior shoulder dislocation: a case report. J Emerg Med. 2009;37(4):400-2.

24. Ballesteros R, Benavente P, Bonsfills N, Chacon M, Garcia-Lazaro FJ. Bilateral anterior dislocation of the shoulder: review of seventy cases and proposal of a new etiological-mechanical classification.JEmerg Med. 2013;44(1):269-79.

25. Meena S, Saini P, Singh V, Kumar R, Trikha V. Bilateral anterior shoulder dislocation. J Nat Sci Biol Med. 2013;4(2):499-501.

26. Moughty AM, O'Connor G. Images in clinical medicine. Bilatera anterior shoulder dislocation. N Engl J Med. 2012;367(8).

27. Dinopoulos HT, Giannoudis PV, Smith RM, Matthews SJ. Bilateral anterior shoulder fracture-dislocation. A case report and a review of the literature. Int Orthop. 1999;23(2):128-30.

28. Devalia KL, Peter VK. Bilateral post traumatic anterior shoulder dislocation. J Postgrad Med. 2005;51(1):72-3.

29. Cresswell TR, Smith RB. Bilateral anterior shoulder dislocations in bench pressing: an unusual cause. BrJ Sports Med.1998;32(1):71-

30. Shears E, Sunderamoorthy D, Ali SA. Brachial plexus injury after anterior shoulder dislocation: a case report. Acta Orthop Belg. 2005;71(4):489-90.

31. Chillemi C, Marinelli M, Galizia P. Fracture-dislocation of the shoulder and brachial plexus palsy: a terrible association. J Orthop Traumatol. 2008;9(4):217-20.

32. Alnot JY. Traumatic brachial plexus palsy in the adult. Retro- and infraclavicular lesions. Clin Orthop Relat Res. 1988(237):9-16.

33. Chung $\mathrm{CH}$. Closed reduction techniques for acute anterior shoulder dislocation: from Egyptians to Australians. Hong Kong JEmerg Med. 2004;11(3):178-88. 